\title{
Ischaemia Reperfusion Injury in Kidney Transplantation
}

\author{
Siddharth Rajakumar and Karen Dwyer \\ Immunology Research Centre \\ St Vincent's Hospital, Melbourne \\ Australia
}

\section{Introduction}

The disruption of an organ's blood supply is obligatory in clinical transplantation occurring at the time of organ procurement. During this ischaemic period complex pathophysiological changes occur within the organ that leave it primed in a pro-inflammatory state. Although the re-establishment of blood flow is essential to halt ongoing ischaemic damage, the organ incurs additional injury. This paradoxical response to reperfusion is known as ischaemia reperfusion injury (IRI).

In deceased-donor transplantation, the haemodynamic instability and cytokine release associated with brain death augment the injury induced by ischaemia, which is more pronounced when donation occurs after cardiac death. Even with donation from a living donor there is a brief period of warm ischaemia after arterial cross-clamping. Following procurement, the donor organ is stored on ice as a means of slowing ischaemic injury. Although cold storage improves organ viability, a new set of complex processes is initiated by the combined effects of ischaemia and hypothermia. These ischaemic periods not only cause hypoxic/anoxic cell injury but lay the foundation for the augmented inflammatory response that occurs during reperfusion.

IRI has a significant impact on both short and long-term transplant outcome. It is a principal cause of delayed graft function which is common in deceased-donor transplantation (Perico, Cattaneo et al. 2004). Delayed graft function occurs in up to $50 \%$ of recipients of kidneys following cardiac death of the donor and primary graft failure occurs in $10 \%$ of these transplants (Keizer, de Fijter et al. 2005). The inflammatory state incited during IRI enhances the immunogenicity of the graft leading to an increased incidence of rejection. The independent association between delayed graft function and graft loss has long been recognised and its influence is more pronounced with concomitant rejection (Halloran, Aprile et al. 1988; Shoskes and Cecka 1998).

The mechanisms which underpin kidney IRI are complex and not yet fully defined. Both necrotic and apoptotic pathways of cell death are implicated and components of the inflammatory cascade, innate immune response, cellular infiltration and activation and the coagulation system are involved. In the kidney, endothelial cells, tubular epithelial cells and 
infiltrating leukocytes all demonstrate specific responses during both ischaemic and reperfusion phases of injury, which amplify the tissue damage. Understanding the mechanisms that mediate IRI is a focus of significant scientific endeavour. Therapeutics based on this research would not only improve the utility of transplantation from a finite donor pool by increasing short and long-term outcomes, but may have applications in numerous other clinical settings. The appeal of therapies that ameliorate the effects of IRI is more pronounced with the increasing use of organs from donors after cardiac death.

\section{Pathophysiological mechanisms in kidney IRI}

\subsection{Apoptosis and necrosis}

Both apoptotic and necrotic cell death occur in kidney IRI. The tubular epithelial cell is particularly susceptible because of the low oxygen tension environment, the concentration of toxic substances and their high adenosine triphosphate (ATP) and oxygen requirements due to transporter activity. These factors confer greatest susceptibility to proximal tubular cells and the outer stripe of the S3 segment (outer medulla) of the kidney which has marginal basal oxygenation. More recently, the lysosomal degradation pathway of autophagy has an emerging role in kidney IRI. Tubular epithelial cells demonstrate autophagy as a response to injury but its role in reperfusion injury is still unclear (Koesters, Kaissling et al. 2010).

Necrotic cell death is initiated by ATP depletion and mitochondrial damage that leads to impaired oxidative phosphorylation and the generation of reactive oxygen species (ROS). These ROS lead to a loss of cell adhesion to other cells and the extra-cellular matrix, damage the plasma membrane and intracellular membranes, and destabilise cytoskeletal proteins. These changes are associated with an increase in intracellular calcium and activation of the calcium-dependent cysteine protease calpain (Shi, Melnikov et al. 2000).

Apoptosis, or programmed cell death, is ATP-dependent and results in the formation of apoptotic bodies by the condensation of cytoplasmic and nuclear components. These bodies induce phagocytosis of the apoptotic cell by surrounding macrophages. As opposed to necrosis which causes cell swelling, apoptosis results in shrinkage of the epithelial cells. While ATP depletion leads to necrotic cell death, the GTP (guanosine triphosphate) depletion noted in kidney IRI promotes apoptotic cell death (Kelly, Plotkin et al. 2001). Cells undergoing apoptosis but lacking the further ATP to proceed with the stages of programmed cell death may undergo secondary necrosis. This may explain why the apoptosis seen in IRI, unlike physiological apoptosis, is associated with inflammation.

Both extrinsic and intrinsic pathways of apoptosis are implicated in IRI and there is considerable cross-talk between them. In kidney IRI receptors that are known to induce extrinsic apoptosis (termed 'death-receptors'), such as the Fas receptor, are up-regulated (Del Rio, Imam et al. 2004). This signalling results in the activation of pro-caspase 8 via the formation of the death-inducing signalling complex (DISC). Caspase 8 subsequently activates caspase 3, 6 and 7 resulting in apoptosis. Inhibition of caspases is protective in IRI (Daemen, van 't Veer et al. 1999; Nicholson 2000). The intrinsic apoptotic pathway largely relates to mitochondrial function. The activation of pro-caspase 9, which triggers intrinsic apoptosis, is initiated by cytochrome $\mathrm{C}$ and the release of cytochrome $\mathrm{C}$ from mitochondria 
is regulated by the Bcl-2 family of proteins (Gogvadze, Robertson et al. 2004). Overexpression of the anti-apoptotic Bcl-2-like protein (BCL-xL) reduces cytochrome $\mathrm{C}$ release from mitochondria and is protective in IRI (Chien, Shyue et al. 2007). The tumoursuppressor protein p53 is activated during hypoxia (by hypoxia inducible factor $1-\alpha$ ). This amplifies the transcription of numerous pro-apoptotic genes such as caspases 6 and 7 (Yang, Kaushal et al. 2008) and Bcl-2. The p53 inhibitor pifithrin- $\alpha$ protects in kidney IRI (Kelly, Plotkin et al. 2003) as does intravenous siRNA treatment directed against p53 in rats (Molitoris, Dagher et al. 2009).

In kidney IRI extrinsic apoptotic, intrinsic apoptotic and regulatory pathways are activated. The outcome in terms of degree of apoptosis clearly relates to the balance between these complex and interacting systems.

\subsection{Inflammation and metabolism}

\subsubsection{Toll-like receptors}

Toll-like receptors (TLRs) are a family of pattern recognition receptors. Endogenous ligands exposed during tissue injury such as heat shock proteins, host DNA, fibronectin and hyaluran can activate some TLRs. Signal transduction from TLRs activates nuclear factor kappa-light-chain-enhancer of activated B cells $(\mathrm{NF} \kappa \mathrm{B})$ leading to the activation of the innate immune system and the generation of pro-inflammatory cytokines. Renal tubular epithelial cells express TLR2 and TLR4 and their expression is up-regulated in IRI (Wolfs, Buurman et al. 2002). Both TLR2 and TLR4 bind heat-shock protein 60 and 70. TLR4 deficiency is protective in renal IRI and adoptive transfer experiments suggest that expression of TLR4 on renal tissue rather than bone-marrow derived cells mediates injury ( $\mathrm{Wu}$, Chen et al. 2007). Both deficiency and inhibition of TLR2 is protective in renal IRI models and TLR-2 mediated damage is, in part, dependent on the adapter protein MyD88 (Leemans, Stokman et al. 2005; Shigeoka, Holscher et al. 2007).

\subsubsection{Cytokines and chemokines}

IRI in the kidney leads to the generation of multiple pro-inflammatory cytokines such as IL-1, IL-6 and TNF $\alpha$ (Takada, Nadeau et al. 1997) by infiltrating and resident leukocytes and endothelial cells. The manifestations of kidney IRI can often be observed systemically and in other organs and is explained, at least in part, by the release of cytokines. Inhibition of IL-1, IL-6 and IL-8 is protective in IRI; conversely, inhibition of IL-4 and IL-10 worsens renal injury (Deng, Kohda et al. 2001).

Chemokines are a sub-family of cytokines that have an emerging role in kidney IRI. Their principal actions relate to leukocyte activation and chemotaxis. The renal expression of the CXC chemokine receptor 3 (CXCR3), which binds several chemokines, monokine, IFN- $\gamma$, IP-10 and CXCL11, is increased after IRI and mice deficient in CXCR3 were protected from an ischaemic insult (Fiorina, Ansari et al. 2006). CX3CL1, a leukocyte chemo-attractant and adhesion molecule, is expressed on T cells, NK cells and monocytes. Its expression is redistributed to the outer medulla in renal IRI and inhibition of its receptor, CX3CR1, attenuated fibrosis after IRI (Furuichi, Gao et al. 2006). Monocyte chemotactic protein 1 (MCP-1) is up-regulated in kidney IRI and deficiency of its receptor (CCR2) attenuated injury and macrophage infiltration (Furuichi, Wada et al. 2003). 


\subsubsection{Complement}

The complement system has a pathogenic role early in renal IRI and all three pathways of activation (classical, alternative and mannose-binding lectin pathways) have been implicated (Farrar, Wang et al. 2004). Specific inhibition of, or deficiency in the alternative pathway protects kidneys in murine models of IRI (Thurman, Ljubanovic et al. 2003). Normally, epithelial cells lining the proximal tubules of the kidney express the complement inhibitor Crry on the basolateral membrane. After renal IRI, Crry is redistributed away from the basolateral surface of the cell, allowing deposition of $\mathrm{C} 3$ (the first component of the alternative pathway). Consistent with this finding, mice deficient in Crry are more susceptible to kidney IRI. C3a also has a role in the production of CXC chemokines by tubular epithelial cells observed after IRI (Thurman, Lenderink et al. 2007). C5a and the membrane attack complex (C5b-9) are implicated in kidney IRI and inhibition of C5a confers protection (Zhou, Farrar et al. 2000; Arumugam, Shiels et al. 2003; De Vries, Matthijsen et al. 2003). Mannose-binding lectin recognizes several endogenous ligands in post-ischaemic renal tissue. These include ligands expressed on apoptotic and necrotic cells and exposed cytokeratin on hypoxic endothelial cells (Moller-Kristensen, Ip et al. 2006). The role of complement is further strengthened by the observation that mice deficient in the complement regulators CD55 and CD59 were more sensitive to renal IRI (Yamada, Miwa et al. 2004).

\subsubsection{Endothelial activation}

The endothelium plays a central role in IRI with effects on inflammation, permeability, coagulation and vascular tone. The endothelial cell subjected to ischaemia undergoes several changes in enzymatic activity, mitochondrial function, cytoskeletal structure, membrane transport, and antioxidant defences. The intensity of endothelial injury may be particularly important in determining the degree of chronic damage that a kidney will develop following IRI. Compared to tubular cells, the regenerative capacity of the renal endothelium is limited which leads to vascular dropout (Horbelt, Lee et al. 2007). Vascular endothelial growth factor (VEGF) inhibitors are induced in ischaemia and, in a rat model of IRI, VEGF treatment attenuated vascular dropout (Basile, Fredrich et al. 2008; Leonard, Friedrich et al. 2008).

Ischaemia activates the endothelium and promotes the expression of various proinflammatory gene products such as cytokines (Pinsky, Yan et al. 1995) and adhesion molecules. More specifically, the expression of ICAM-1 (Kelly, Williams et al. 1996), Pselectin (Takada, Nadeau et al. 1997) and E-selectin (Singbartl and Ley 2000) is up-regulated and antibody blockade of ICAM-1 significantly attenuated IRI in rats.

Endothelium-dependent vasodilatation, mediated by nitric oxide (NO), is impaired in arterioles following IRI (Pang, Wu et al. 2000) and the disordered auto-regulation can persist for up to 1 week. In addition to vasodilatory effects, NO is both cytoprotective (antioxidant activity) and cytotoxic (by the production of peroxynitrite) and can inhibit neutrophilmediated injury. These varying effects, which make the precise role of NO in IRI difficult to define, are in part due to differences between the isoforms of the NO synthase. In ischaemia, due to endothelial damage there is a reduction in endothelial nitric oxide synthase (eNOS) and a relative increase in inducible NOS (iNOS) and this imbalance is considered to 
contribute to injury, in part, by enhancing the thrombogenic tendancy of the endothelium (Goligorsky, Brodsky et al. 2004). Both deficiency and inhibition of iNOS protect in kidney IRI (Noiri, Peresleni et al. 1996; Ling, Edelstein et al. 1999). Furthermore, a NO inhibitor worsened, and treatment with the NOS substrate, L-arginine, attenuated kidney IRI in rats (Ogawa, Nussler et al. 2001; Chander and Chopra 2005).

The permeability of the endothelial barrier separating the capillary lumen from the interstitial space is increased in IRI. In vivo imaging studies suggest that this effect is maximal 24 hours after ischaemic injury and occurs within 2-4 hours (Sutton, Mang et al. 2003). A loss in the integrity of adeherens junctions as shown by the delocalisation of the adhesion molecule cadherin between endothelial cells was noted. Thus, the increased vascular permeability predominantly relates to para-cellular, rather than trans-cellular pathways. A role for the matrix metalloproteinases 2 and 9 has been postulated as their activation correlates with microvascular permeability. In murine IRI, an inhibitor of matrix metalloproteinase (minocycline) attenuated microvascular permeability (Sutton, Kelly et al. 2005).

\subsubsection{Adenosine generation and signalling}

Ischaemic injury results in the extrusion and transport of intra-cellular adenosine triphosphate (ATP) from injured or dying cells into the extra-cellular space. Here it undergoes serial hydrolysis by the ecto-enzyme CD39 (ectonucleoside-triphosphatediphosphohydrolase-1) generating adenosine diphosphate (ADP) and adenosine monophosphate (AMP). AMP is further hydrolysed by the ecto-enzyme CD73 (ecto-5'nucleotidase) generating adenosine (Zimmermann 1992; Kaczmarek, Koziak et al. 1996). The concentration of adenosine, which acts at 4 receptors, is therefore increased in ischaemia and is thought to provide adaptive responses to hypoxia and attenuate inflammation and apoptosis by several intra-cellular second messenger pathways. Conversely, signalling by ATP and ADP at P2 purinergic receptors have pro-inflammatory and pro-thrombotic effects. Although adenosine treatment has been shown to be protective in IRI models (Lee and Emala 2000), its extremely short half-life and systemic haemodynamic effects in vivo makes its clinical application difficult.

Manipulating the metabolic pathway of adenosine generation can influence kidney IRI. Transgenic over-expression of CD39 was protective in both warm and cold kidney IRI models. This finding is supported by the protection conferred by treatment with Apyrase (which provides CD39 enzymatic activity) and the severe injury noted in mice deficient in CD39 (Lu, Rajakumar et al. 2008; Crikis, Lu et al. 2010). CD73 is up-regulated in ischaemia by hypoxia-inducible factor 1 (Thompson, Eltzschig et al. 2004) and is thought to be part of an innate protective mechanism during hypoxia. Although soluble CD73 (5' nucleotidase) treatment was protective in a murine kidney IRI model, this is inconsistent with other studies demonstrating protection with CD73 deficiency or inhibition. This may relate to differences in the IRI models (Van Waarde, Stromski et al. 1989; Grenz, Zhang et al. 2007; Rajakumar, Lu et al. 2010).

All four adenosine receptors are present in the kidney and expression is up-regulated by ischaemia. The precise localisation of each receptor has proven difficult but there is evidence that the $\mathrm{A} 1$ and $\mathrm{A} 2 \mathrm{~B}$ receptors are the dominant receptors in the pre-glomerular vasculature 
(Jackson, Zhu et al. 2002) and that A2B receptor expression is more prominent on the renal vasculature than the tubular epithelial cells (Grenz, Osswald et al. 2008).

A1 receptor activation has generally been protective in kidney IRI. Mice deficient in the A1 receptor develop worse injury which is reversed by lentiviral reconstitution of the A1 receptor in the kidney (Kim, Chen et al. 2009). A1 receptor agonist treatment was protective in a mouse kidney IRI model. Treatment conferred both acute and delayed protection, interestingly, by different signalling mechanisms (Joo, Kim et al. 2007). A2A receptor signalling is also protective in kidney IRI. Adoptive transfer experiments using wild-type and $\mathrm{A} 2 \mathrm{~A}$ receptor deficient mice in a kidney IRI model demonstrated A2A expression on bone-marrow derived cells mediates the protective effect (Day, Huang et al. 2003). Furthermore, a specific protective role for the A2A receptor on CD4+ T lymphocytes has been demonstrated (Day, Huang et al. 2006). Regulatory T lymphocytes have a protective role in kidney IRI and A2A receptor signalling is known to promote their expansion (Zarek, Huang et al. 2008).

The A2B receptor has a lower affinity for adenosine than the other receptors and so may play a more prominent role in pathological states where there is increased adenosine generation. A2B receptor agonist treatment was protective in a mouse model of kidney IRI and a specific role in the protective phenomenon of ischaemic preconditioning was demonstrated. In contrast to the $\mathrm{A} 2 \mathrm{~A}$ receptor studies, adoptive transfer experiments localised the protective effect to $\mathrm{A} 2 \mathrm{~B}$ receptors on the renal parenchyma rather than infiltrating cells (Grenz, Osswald et al. 2008). The A3 receptor mediates injury in kidney IRI. Antagonist treatment protected, while agonist treatment worsened injury in a mouse model (Lee and Emala 2000).

\subsubsection{Oxidative stress}

In IRI, reperfusion is a trigger for the generation of reactive oxygen species (ROS) that mediate cell injury directly by lipid peroxidation of cellular membranes. ROS can increase activation, chemotaxis and endothelial adherence by stimulating adhesion molecules and cytokine gene expression through the activation of transcription factors such as NFKB (Toyokuni 1999).

Haemoxygenase $(\mathrm{HO})$ is an enzyme that degrades haem to produce carbon monoxide, biliverdin and bilirubin. Free haem can mediate cellular toxicity whilst the metabolic products are generally cytoprotective (Sikorski, Hock et al. 2004). Specifically, bilirubin is protective in a rat model of kidney IRI; HO-up-regulation confers cytoprotection in the kidney and carbon monoxide induces HIF- $\alpha$ which up-regulates $\mathrm{HO}$ and over 100 other cytoprotective genes (Blydt-Hansen, Katori et al. 2003). Furthermore, carbon monoxide therapy was protective in a kidney transplant model (Neto, Nakao et al. 2006). Regulatory $T$ cells have been shown to play a protective role in kidney IRI and HO expression on antigenpresenting cells has been shown to be necessary for their full suppressive ability (George, Braun et al. 2008; Kinsey, Huang et al. 2010).

The xanthine oxidase $(\mathrm{XO})$ system is the major source of ROS production in mammals. During the ischaemic period, intracellular ATP is catabolised to hypoxanthine and hypoxic stress triggers the conversion of xanthine dehydrogenase $(\mathrm{XDH})$ to the oxygen radical- 
producing XO (Younes, Schoenberg et al. 1984). During reperfusion, oxygen is reintroduced into the tissue, where it reacts with hypoxanthine and $\mathrm{XO}$ to produce a burst of oxygen free radicals; superoxide anion $\left(\mathrm{O}^{2-}\right)$ and hydrogen peroxide $\left(\mathrm{H}_{2} \mathrm{O}_{2}\right)$ (Harrison 2002). Under physiological conditions, the damaging effects of $\mathrm{O}^{2-}$ are prevented in part by superoxide dismutase (SOD), which converts $\mathrm{O}^{2-}$ to $\mathrm{H}_{2} \mathrm{O}_{2}$. During reperfusion of ischaemic tissues, the capacity of these antioxidant pathways is exceeded leading to cellular injury and death. Mice deficient in SOD3 were shown to have increased oxidative stress and tubular cast formation in IRI (Schneider, Sullivan et al. 2010).

\subsubsection{Peroxisome proliferator-activated receptors}

The family of peroxisome proliferator-activated receptors (PPARs) nuclear hormone receptors play a regulatory role in inflammatory responses, lipid metabolism, cellular differentiation and cell survival and have attracted increasing attention in IRI. PPAR $\alpha$ deficient mice have worse injury in kidney IRI (Portilla, Dai et al. 2000) while treatment with PPAR- $\alpha$ ligand or over-expression in the proximal tubules confers protection (Sivarajah, Chatterjee et al. 2002; Li, Nagothu et al. 2009). PPAR $\gamma$ agonist treatment protects in kidney IRI and PPAR $\beta / \delta$ activity is also protective (Sivarajah, Chatterjee et al. 2003; Letavernier, Perez et al. 2005).

\subsection{Cellular mediators}

\subsubsection{Neutrophils, macrophages, dendritic cells and natural killer cells}

Early infiltration of neutrophils into the post-ischaemic kidney has been demonstrated (Chiao, Kohda et al. 1997) and likely contributes to kidney IRI by the release of reactive oxygen species and proteases and by obstructing flow in the renal microvasculature. Inhibiting neutrophil infiltration is protective (Kelly, Williams et al. 1996) however only partial protection was observed with neutrophil blockade or depletion (Thornton, Winn et al. 1989).

The role of macrophages in renal IRI is via the production of pro-inflammatory cytokines (IL-1 $\alpha$, IL-6, IL-12p40/70, TNF $\alpha$ ) and activation of other leucocytes. Macrophages infiltrate the kidney early in IRI (within 1 hour) and particularly target the outer medulla. The infiltration is mediated by CCR2 and CX3CR1 signalling ( $\mathrm{Li}$, Huang et al. 2008; Oh, Dursun et al. 2008). Depletion of macrophages prior to IRI prevents injury and reconstitution restores it (Day, Huang et al. 2005).

Dendritic cells (DC) form a link between the innate and adaptive arms of the immune system and are the most abundant resident leukocyte in the kidney interstitium. In particular, CD11c+MHC ClassII+ DC are abundant in the murine kidney suggesting an important role in regulating renal immunity and inflammation. Upon stimulation DCs becomes mature with phenotypic characteristics of increased expression of MHC Class II and co-stimulation molecules, the release pro-inflammatory factors and the ability to activate NKT cells (Dong, Swaminathan et al. 2005). Renal DC produce TNF- $\alpha$, IL-6, C-C motif chemokine 2 and C-C motif chemokine 5 in kidney IRI and the amount of TNF- $\alpha$ produced after ischaemia is reduced after depletion of DCs (Dong, Swaminathan et al. 2007).

Natural killer cells (NK) are cytotoxic lymphocytes without B or T cell receptors. Infiltration by NK cells has been noted by 4 hours and depletion of NK cells protects in kidney IRI in a perforin-dependent manner (Zhang, Wang et al. 2008). 


\subsubsection{CD4+ effector T lymphocytes}

Lymphocytes are the major mediators of adaptive immunity and so were initially not thought to contribute to IRI. Their significant role in IRI was, however, established with the demonstration that mice deficient in T cells are protected from IRI and the adoptive transfer of $\mathrm{T}$ cells restores injury (Burne-Taney, Yokota-Ikeda et al. 2005). Further confirmation of the importance of T cells in the pathogenesis of IRI is that the use of CTLA4-Ig to block the B7-CD28 co-stimulation of T cells significantly attenuates renal dysfunction (Ysebaert, De Greef et al. 2004) as does use of a monoclonal antibody specific to B7 (De Greef, Ysebaert et al. 2001). The Th1 subset of T lymphocytes that produce IFN $\gamma$ are deleterious, while IL4 producing Th2 cells are protective in IRI (Yokota, Burne-Taney et al. 2003). Further confirmation of this is that adoptive transfer of CD4+ cells lacking CD28 are unable to restore this injury, as are CD4+ cells from IFN $\gamma$ knock-out mice (Burne, Daniels et al. 2001).

In murine renal IRI the number of invariant NKT cells (cells that possess a conserved invariant $\mathrm{T}$ cell receptor together with the NK cell marker NK1.1) is significantly increased at 3 hours of reperfusion following 30 minutes of ischaemia and inhibition or depletion of this cell type prevents injury. NKT cell activation was reported to contribute to kidney injury by mediating neutrophil IFN $\gamma$ production (Li, Huang et al. 2007).

The minor T cell subsets, the $\gamma-\delta$ T cell and the $\alpha-\beta$ T cell have a poorly understood role in kidney IRI. Deficiencies of these cell subsets have conferred protection (Savransky, Molls et al. 2006; Hochegger, Schatz et al. 2007).

\subsubsection{Regulatory $\mathrm{T}$ cells}

Regulatory T cells (Treg), known for their ability to suppress immune responsiveness, play a specific role in kidney IRI. Infiltration of Tregs was demonstrated 3 and 10 days after kidney IRI. Depletion of Tregs 24 hours after IRI resulted in increased tubular damage and cytokine production by infiltrating $\mathrm{T}$ effector cells. Infusion of Tregs resulted in early improvements in cytokine production and a late functional protective effect (Gandolfo, Jang et al. 2009). Correlating with this, Treg depletion was associated with an increased accumulation of neutrophils and macrophages, and increased inflammatory cytokine transcription, and Treg infusion prior to IRI attenuated inflammatory responses (Kinsey, Huang et al. 2010).

\subsubsection{B lymphocytes}

In kidney IRI the role of B lymphocytes remains unclear. They play a pathogenic role that relates to the production of natural antibodies, which develop without antigen stimulation. This is predominantly by B1 cells which are located in the pleural and peritoneal cavities. Depletion of peritoneal B1 cells reduced glomerular IgM deposition and protected mice from IRI. Conversely, the more abundant B2 cells likely play a protective role in kidney IRI mediated by IL-10 release (Renner, Strassheim et al. 2010).

\subsection{Coagulation}

Activation of the coagulation system has been noted in several IRI models. Ischaemia leads to a reduction in the expression of the anticoagulant thrombomodulin, the down-regulation of the endothelial protein $\mathrm{C}$ receptor (EPCR) and the up-regulation of tissue factor (Ogawa, 
Shreeniwas et al. 1990). Thrombosis leads to further endothelial dysfunction and reduced tissue perfusion. Although anticoagulants such as heparin have been shown to be protective in IRI, the mechanism of protection relates to complement inhibition, the prevention of endothelial cell dysfunction and the release of vasoactive mediators from the endothelium, rather than direct anticoagulant effects (Kouretas, Kim et al. 1999). Kidney IRI was attenuated by soluble thrombomodulin treatment either before or after ischaemia. This was associated with reduced leukocyte adhesion and endothelial permeability and improved microvascular flow but was independent of its ability to generate activated protein C (APC) (Sharfuddin, Sandoval et al. 2009). Treatment with APC, which acts at the EPCR, is protective in a rat kidney IRI model. Again, the effect was considered to be independent of its anti-coagulant activity (Mizutani, Okajima et al. 2000).

\section{Therapeutic implications}

Based on recent advances in the understanding of the mechanistic basis of kidney IRI, several novel therapeutic approaches are being developed. Delineating the apoptotic cell death pathway has led to a pancaspase inhibitor and a p53 inhibitor that are currently in clinical trials for liver transplantation. The field of adenosine signalling is promising and an adenosine $2 \mathrm{~A}$ receptor agonists is already available for myocardial diagnostic studies and selective adenosine $2 \mathrm{~B}$ receptor agonists are being developed. The protective metabolic and anti-inflammatory effects of PPAR signalling have been demonstrated in murine kidney IRI models. Given thiazolidenediones (PPAR $\gamma$ ligand) and fibrates (PPAR $\alpha$ ligand) are already available, this demonstrates the capacity for basic research in kidney IRI to identify potential new applications for existing treatments. Similarly, statin (HMG-CoA reductase inhibitor) therapy is widely used for dyslipidaemia and preclinical studies suggest it is protective in kidney IRI (Yokota, O'Donnell et al. 2003). The mechanism of protection is unrelated to cholesterol lowering and may relate to caspase-3 mediated anti-apoptotic effects (Haylor, Harris et al. 2011). Donor treatment with simvastatin is currently under investigation (NCT01160978).

Although erythropoietin treatment has a body of pre-clinical evidence suggesting protective effects (Sharples, Patel et al. 2004), clinical trials in both acute kidney injury and kidney transplantation have been disappointing to date (Endre, Walker et al. 2010; Martinez, Kamar et al. 2010). A greater understanding of the pathways of oxidative stress in kidney IRI have led to a focus on carbon monoxide. Given its systemic toxicity, donor compounds are being developed that may allow carbon monoxide release at the ischaemic tissue. Along a similar line, several anti-oxidant agents are currently being investigated. The significant role played by the complement system in several disease states has led to the development of treatments such as eculizumab (recombinant antibody targeting C5). This is being trialled in several clinical settings including kidney transplantation (Weitz, Amon et al. 2011).

Modulating cellular interactions, such us the endothelial-leukocyte adhesion, is promising based on pre-clinical studies in kidney IRI. Antibody blockade of ICAM1 showed disappointing results in an early trial (Salmela, Wramner et al. 1999). A recombinant blocking antibody to P-selectin has recently completed a phase 2 trial although an effect on delayed graft function has not yet been demonstrated (Osama Gaber, Mulgaonkar et al. 2011). The emerging role of $T$ lymphocytes in kidney IRI has meant that inhibiting early $T$ lymphocyte activation is a focus of investigation. Anti-thymocyte globulin induction for 
kidney transplantation has shown promising results and clinical trials are ongoing (NCT00733733/NCT01149993). Similarly, numerous agents that reduce $\mathrm{T}$ lymphocyte activation by blocking co-stimulation are under development. Belatacept, which prevents co-stimulation by binding to CD80 and CD86 on antigen-presenting cells was recently approved by the FDA for use in kidney transplant recipients (Vincenti, Dritselis et al. 2011).

Cell-based therapies show significant promise. On a background of positive pre-clinical studies (Togel, Hu et al. 2005), a clinical trial of autologous mesenchymal stem cell infusion in kidney transplantation is underway (NCT00752479). Haemopoietic stem cells, which may promote endothelial/microvascular repair also show promise (Becherucci, Mazzinghi et al. 2009). The recent pre-clinical finding that regulatory T cells protect in kidney IRI suggests ex-vivo expansion and infusion may also have therapeutic potential.

In addition to the recognized protective effects of hypothermia, insights into IRI mechanisms may improve reperfusion injury following cold ischaemia by modifying organ preservation methods. The University of Wisconsin (UW) solution widely used for preservation contains anti-oxidant ingredients such as allopurinol and glutathione. It also contains adenosine which may mediate cytoprotective effects. The addition of lecithinized SOD to the cold ischaemia preservation fluid improved early inflammation and later proteinuria and apoptosis in a rat kidney transplant model (Nakagawa, Koo et al. 2002). Similarly, carbon monoxide supplementation to UW preservation fluid led to improved histological damage and inflammatory responses in a pig transplant model (Yoshida, Ozaki et al. 2010). As an example of perfusion mediated protection, Yamauchi et al showed that flushing with the fibrinolytic agent streptokinase conferred protection in a non-heart beating donor rat kidney transplant model (Yamauchi, Schramm et al. 2003). A current clinical trial includes an experimental arm with infusion of the donor kidney with thymoglobulin which may attenuate T lymphocyte mediated injury with reperfusion (NCT01149993).

Brief periods of ischaemia can protect an organ from a subsequent ischaemic insult. This phenomenon is known as ischaemic preconditioning (IP) and was originally described in canine hearts (Murry, Jennings et al. 1986). Protection by IP in a murine model of renal IRI has been demonstrated using cycles of renal artery occlusion (Grenz, Eckle et al. 2007). Protection of an organ from an ischaemic insult is also observed when the cycles of shortterm ischaemia are applied to a different anatomical site. This phenomenon is termed remote ischaemic preconditioning (RIP). Renal protection by RIP has been reported by cycles of ischaemia in the contra-lateral kidney in mice (Park, Chen et al. 2001). Several studies in humans have demonstrated the clinical applicability of RIP. A recent study demonstrated that cycles of lower limb ischaemia led to reduced ischaemic kidney injury in patients undergoing cardiac surgery (Zimmerman, Ezeanuna et al. 2011). While the phenomenon may be applied to transplantation, research into the mechanisms mediating RIP should also provide targets for future therapeutic strategies. Regulatory $\mathrm{T}$ cells play a dominant role in IP (Kinsey, Huang et al. 2010) as do CD39, CD73 and adenosine A2B receptor signalling (Grenz, Zhang et al. 2007; Grenz, Zhang et al. 2007; Grenz, Osswald et al. 2008). In various IRI models ATP-dependent potassium channels (Pell, Baxter et al. 1998), protein kinase C (Weinbrenner, Nelles et al. 2002), nitric oxide synthesis (Wang, Xu et al. 2001), bradykinin, heat shock proteins (Patel, van de Poll et al. 2004), haemoxygenase-1 (Amersi, Buelow et al. 1999) and TNFa (Teoh, Leclercq et al. 2003) have all been implicated. Clinical trials of remote preconditioning in kidney transplantation are currently underway (NCT01395719, NCT01289548). 


\section{Conclusion}

Kidney ischaemia reperfusion injury is obligatory in transplantation. Given the significant impact of IRI on both short and long-term graft function, therapeutic strategies to minimise IRI are of considerable appeal. This is particularly relevant with the increasing utilisation of organs from extended-criteria/non-heart-beating donors. However, the pathophysiological mechanisms mediating kidney IRI are complex and involve the interaction of numerous biological systems. Novel insights regarding these interactions are leading to the development of applications to attenuate IRI in the fields of therapeutics, organ preservation and ischaemic preconditioning.

\section{References}

Amersi, F., R. Buelow, et al. (1999). "Upregulation of heme oxygenase-1 protects genetically fat Zucker rat livers from ischemia/reperfusion injury." J Clin Invest 104(11): 16311639.

Arumugam, T. V., I. A. Shiels, et al. (2003). "A small molecule C5a receptor antagonist protects kidneys from ischemia/reperfusion injury in rats." Kidney Int 63(1): 134142.

Basile, D. P., K. Fredrich, et al. (2008). "Renal ischemia reperfusion inhibits VEGF expression and induces ADAMTS-1, a novel VEGF inhibitor." Am J Physiol Renal Physiol 294(4): F928-936.

Becherucci, F., B. Mazzinghi, et al. (2009). "The role of endothelial progenitor cells in acute kidney injury." Blood Purif 27(3): 261-270.

Blydt-Hansen, T. D., M. Katori, et al. (2003). "Gene transfer-induced local heme oxygenase-1 overexpression protects rat kidney transplants from ischemia/reperfusion injury." J Am Soc Nephrol 14(3): 745-754.

Burne-Taney, M. J., N. Yokota-Ikeda, et al. (2005). "Effects of combined T- and B-cell deficiency on murine ischemia reperfusion injury." Am J Transplant 5(6): 1186-1193.

Burne, M. J., F. Daniels, et al. (2001). "Identification of the CD4(+) T cell as a major pathogenic factor in ischemic acute renal failure." J Clin Invest 108(9): 1283-1290.

Chander, V. and K. Chopra (2005). "Renal protective effect of molsidomine and L-arginine in ischemia-reperfusion induced injury in rats." J Surg Res 128(1): 132-139.

Chiao, H., Y. Kohda, et al. (1997). "Alpha-melanocyte-stimulating hormone protects against renal injury after ischemia in mice and rats." J Clin Invest 99(6): 1165-1172.

Chien, C. T., S. K. Shyue, et al. (2007). "Bcl-xL augmentation potentially reduces ischemia/reperfusion induced proximal and distal tubular apoptosis and autophagy." Transplantation 84(9): 1183-1190.

Crikis, S., B. Lu, et al. (2010). "Transgenic overexpression of CD39 protects against renal ischemia-reperfusion and transplant vascular injury." Am J Transplant 10(12): 25862595.

Daemen, M. A., C. van 't Veer, et al. (1999). "Inhibition of apoptosis induced by ischemiareperfusion prevents inflammation." J Clin Invest 104(5): 541-549.

Day, Y. J., L. Huang, et al. (2003). "Renal protection from ischemia mediated by A2A adenosine receptors on bone marrow-derived cells." J Clin Invest 112(6): 883-891. 
Day, Y. J., L. Huang, et al. (2006). "Renal ischemia-reperfusion injury and adenosine 2A receptor-mediated tissue protection: the role of CD4+ T cells and IFN-gamma." J Immunol 176(5): 3108-3114.

Day, Y. J., L. Huang, et al. (2005). "Renal ischemia-reperfusion injury and adenosine 2A receptor-mediated tissue protection: role of macrophages." Am J Physiol Renal Physiol 288(4): F722-731.

De Greef, K. E., D. K. Ysebaert, et al. (2001). "Anti-B7-1 blocks mononuclear cell adherence in vasa recta after ischemia." Kidney Int 60(4): 1415-1427.

De Vries, B., R. A. Matthijsen, et al. (2003). "Inhibition of complement factor C5 protects against renal ischemia-reperfusion injury: inhibition of late apoptosis and inflammation." Transplantation 75(3): 375-382.

Del Rio, M., A. Imam, et al. (2004). "The death domain of kidney ankyrin interacts with Fas and promotes Fas-mediated cell death in renal epithelia." J Am Soc Nephrol 15(1): 4151.

Deng, J., Y. Kohda, et al. (2001). "Interleukin-10 inhibits ischemic and cisplatin-induced acute renal injury." Kidney Int 60(6): 2118-2128.

Dong, X., S. Swaminathan, et al. (2005). "Antigen presentation by dendritic cells in renal lymph nodes is linked to systemic and local injury to the kidney." Kidney Int 68(3): 1096-1108.

Dong, X., S. Swaminathan, et al. (2007). "Resident dendritic cells are the predominant TNFsecreting cell in early renal ischemia-reperfusion injury." Kidney Int 71(7): 619-628.

Endre, Z. H., R. J. Walker, et al. (2010). "Early intervention with erythropoietin does not affect the outcome of acute kidney injury (the EARLYARF trial)." Kidney Int 77(11): 1020-1030.

Farrar, C. A., Y. Wang, et al. (2004). "Independent pathways of P-selectin and complementmediated renal ischemia/reperfusion injury." Am J Pathol 164(1): 133-141.

Fiorina, P., M. J. Ansari, et al. (2006). "Role of CXC chemokine receptor 3 pathway in renal ischemic injury." J Am Soc Nephrol 17(3): 716-723.

Furuichi, K., J. L. Gao, et al. (2006). "Chemokine receptor CX3CR1 regulates renal interstitial fibrosis after ischemia-reperfusion injury." Am J Pathol 169(2): 372-387.

Furuichi, K., T. Wada, et al. (2003). "CCR2 signaling contributes to ischemia-reperfusion injury in kidney." J Am Soc Nephrol 14(10): 2503-2515.

Gandolfo, M. T., H. R. Jang, et al. (2009). "Foxp3+ regulatory T cells participate in repair of ischemic acute kidney injury." Kidney Int 76(7): 717-729.

George, J. F., A. Braun, et al. (2008). "Suppression by CD4+CD25+ regulatory T cells is dependent on expression of heme oxygenase- 1 in antigen-presenting cells." Am J Pathol 173(1): 154-160.

Gogvadze, V., J. D. Robertson, et al. (2004). "Mitochondrial cytochrome c release may occur by volume-dependent mechanisms not involving permeability transition." Biochem J 378(Pt 1): 213-217.

Goligorsky, M. S., S. V. Brodsky, et al. (2004). "NO bioavailability, endothelial dysfunction, and acute renal failure: new insights into pathophysiology." Semin Nephrol 24(4): 316-323.

Grenz, A., T. Eckle, et al. (2007). "Use of a hanging-weight system for isolated renal artery occlusion during ischemic preconditioning in mice." Am J Physiol Renal Physiol 292(1): F475-485. 
Grenz, A., H. Osswald, et al. (2008). "The reno-vascular A2B adenosine receptor protects the kidney from ischemia." PLoS Med 5(6): e137.

Grenz, A., H. Zhang, et al. (2007). "Protective role of ecto-5'-nucleotidase (CD73) in renal ischemia." J Am Soc Nephrol 18(3): 833-845.

Grenz, A., H. Zhang, et al. (2007). "Contribution of E-NTPDase1 (CD39) to renal protection from ischemia-reperfusion injury." FASEB J 21(11): 2863-2873.

Halloran, P. F., M. A. Aprile, et al. (1988). "Early function as the principal correlate of graft survival. A multivariate analysis of 200 cadaveric renal transplants treated with a protocol incorporating antilymphocyte globulin and cyclosporine." Transplantation 46(2): 223-228.

Harrison, R. (2002). "Structure and function of xanthine oxidoreductase: where are we now?" Free Radic Biol Med 33(6): 774-797.

Haylor, J. L., K. P. Harris, et al. (2011). "Atorvastatin improving renal ischemia reperfusion injury via direct inhibition of active caspase-3 in rats." Exp Biol Med (Maywood) 236(6): 755-763.

Hochegger, K., T. Schatz, et al. (2007). "Role of alpha/beta and gamma/delta T cells in renal ischemia-reperfusion injury." Am J Physiol Renal Physiol 293(3): F741-747.

Horbelt, M., S. Y. Lee, et al. (2007). "Acute and chronic microvascular alterations in a mouse model of ischemic acute kidney injury." Am J Physiol Renal Physiol 293(3): F688-695.

Jackson, E. K., C. Zhu, et al. (2002). "Expression of adenosine receptors in the preglomerular microcirculation." Am J Physiol Renal Physiol 283(1): F41-51.

Joo, J. D., M. Kim, et al. (2007). "Acute and delayed renal protection against renal ischemia and reperfusion injury with A1 adenosine receptors." Am J Physiol Renal Physiol 293(6): F1847-1857.

Kaczmarek, E., K. Koziak, et al. (1996). "Identification and characterization of CD39/vascular ATP diphosphohydrolase." J Biol Chem 271(51): 33116-33122.

Keizer, K. M., J. W. de Fijter, et al. (2005). "Non-heart-beating donor kidneys in the Netherlands: allocation and outcome of transplantation." Transplantation 79(9): 1195-1199.

Kelly, K. J., Z. Plotkin, et al. (2001). "Guanosine supplementation reduces apoptosis and protects renal function in the setting of ischemic injury." J Clin Invest 108(9): 12911298.

Kelly, K. J., Z. Plotkin, et al. (2003). "P53 mediates the apoptotic response to GTP depletion after renal ischemia-reperfusion: protective role of a p53 inhibitor." J Am Soc Nephrol 14(1): 128-138.

Kelly, K. J., W. W. Williams, Jr., et al. (1996). "Intercellular adhesion molecule-1-deficient mice are protected against ischemic renal injury." J Clin Invest 97(4): 1056-1063.

Kim, M., S. W. Chen, et al. (2009). "Kidney-specific reconstitution of the A1 adenosine receptor in A1 adenosine receptor knockout mice reduces renal ischemiareperfusion injury." Kidney Int 75(8): 809-823.

Kinsey, G. R., L. Huang, et al. (2010). "Regulatory T cells contribute to the protective effect of ischemic preconditioning in the kidney." Kidney Int 77(9): 771-780.

Koesters, R., B. Kaissling, et al. (2010). "Tubular overexpression of transforming growth factor-beta1 induces autophagy and fibrosis but not mesenchymal transition of renal epithelial cells." Am J Pathol 177(2): 632-643. 
Kouretas, P. C., Y. D. Kim, et al. (1999). "Nonanticoagulant heparin prevents coronary endothelial dysfunction after brief ischemia-reperfusion injury in the dog." Circulation 99(8): 1062-1068.

Lee, H. T. and C. W. Emala (2000). "Protective effects of renal ischemic preconditioning and adenosine pretreatment: role of $\mathrm{A}(1)$ and $\mathrm{A}(3)$ receptors." Am J Physiol Renal Physiol 278(3): F380-387.

Leemans, J. C., G. Stokman, et al. (2005). "Renal-associated TLR2 mediates ischemia/reperfusion injury in the kidney." J Clin Invest 115(10): 2894-2903.

Leonard, E. C., J. L. Friedrich, et al. (2008). "VEGF-121 preserves renal microvessel structure and ameliorates secondary renal disease following acute kidney injury." Am J Physiol Renal Physiol 295(6): F1648-1657.

Letavernier, E., J. Perez, et al. (2005). "Peroxisome proliferator-activated receptor beta/delta exerts a strong protection from ischemic acute renal failure." J Am Soc Nephrol 16(8): 2395-2402.

Li, L., L. Huang, et al. (2007). "NKT cell activation mediates neutrophil IFN-gamma production and renal ischemia-reperfusion injury." J Immunol 178(9): 5899-5911.

Li, L., L. Huang, et al. (2008). "The chemokine receptors CCR2 and CX3CR1 mediate monocyte/macrophage trafficking in kidney ischemia-reperfusion injury." Kidney Int 74(12): 1526-1537.

Li, S., K. K. Nagothu, et al. (2009). "Transgenic expression of proximal tubule peroxisome proliferator-activated receptor-alpha in mice confers protection during acute kidney injury." Kidney Int 76(10): 1049-1062.

Ling, H., C. Edelstein, et al. (1999). "Attenuation of renal ischemia-reperfusion injury in inducible nitric oxide synthase knockout mice." Am J Physiol 277(3 Pt 2): F383-390.

Lu, B., S. V. Rajakumar, et al. (2008). "The impact of purinergic signaling on renal ischemiareperfusion injury." Transplantation 86(12): 1707-1712.

Martinez, F., N. Kamar, et al. (2010). "High dose epoetin beta in the first weeks following renal transplantation and delayed graft function: Results of the Neo-PDGF Study." Am J Transplant 10(7): 1695-1700.

Mizutani, A., K. Okajima, et al. (2000). "Activated protein C reduces ischemia/reperfusioninduced renal injury in rats by inhibiting leukocyte activation." Blood 95(12): 37813787.

Molitoris, B. A., P. C. Dagher, et al. (2009). "siRNA targeted to p53 attenuates ischemic and cisplatin-induced acute kidney injury." J Am Soc Nephrol 20(8): 1754-1764.

Moller-Kristensen, M., W. K. Ip, et al. (2006). "Deficiency of mannose-binding lectin greatly increases susceptibility to postburn infection with Pseudomonas aeruginosa." $J$ Immunol 176(3): 1769-1775.

Murry, C. E., R. B. Jennings, et al. (1986). "Preconditioning with ischemia: a delay of lethal cell injury in ischemic myocardium." Circulation 74(5): 1124-1136.

Nakagawa, K., D. D. Koo, et al. (2002). "Lecithinized superoxide dismutase reduces cold ischemia-induced chronic allograft dysfunction." Kidney Int 61(3): 1160-1169.

Neto, J. S., A. Nakao, et al. (2006). "Low-dose carbon monoxide inhalation prevents development of chronic allograft nephropathy." Am J Physiol Renal Physiol 290(2): F324-334.

Nicholson, D. W. (2000). "From bench to clinic with apoptosis-based therapeutic agents." Nature 407(6805): 810-816. 
Noiri, E., T. Peresleni, et al. (1996). "In vivo targeting of inducible NO synthase with oligodeoxynucleotides protects rat kidney against ischemia." J Clin Invest 97(10): 2377-2383.

Ogawa, S., R. Shreeniwas, et al. (1990). "The effect of hypoxia on capillary endothelial cell function: modulation of barrier and coagulant function." Br J Haematol 75(4): 517524.

Ogawa, T., A. K. Nussler, et al. (2001). "Contribution of nitric oxide to the protective effects of ischemic preconditioning in ischemia-reperfused rat kidneys." J Lab Clin Med 138(1): 50-58.

Oh, D. J., B. Dursun, et al. (2008). "Fractalkine receptor (CX3CR1) inhibition is protective against ischemic acute renal failure in mice." Am J Physiol Renal Physiol 294(1): F264271.

Osama Gaber, A., S. Mulgaonkar, et al. (2011). "YSPSL (rPSGL-Ig) for improvement of early renal allograft function: a double-blind, placebo-controlled, multi-center Phase IIa study(1,2,3)." Clin Transplant 25(4): 523-533.

Pang, S. T., M. S. Wu, et al. (2000). "University of Wisconsin preservation solution enhances intrarenal nitric oxide production." Transplant Proc 32(7): 1617-1618.

Park, K. M., A. Chen, et al. (2001). "Prevention of kidney ischemia/reperfusion-induced functional injury and JNK, p38, and MAPK kinase activation by remote ischemic pretreatment." J Biol Chem 276(15): 11870-11876.

Patel, A., M. C. van de Poll, et al. (2004). "Early stress protein gene expression in a human model of ischemic preconditioning." Transplantation 78(10): 1479-1487.

Pell, T. J., G. F. Baxter, et al. (1998). "Renal ischemia preconditions myocardium: role of adenosine receptors and ATP-sensitive potassium channels." Am J Physiol 275(5 Pt 2): H1542-1547.

Perico, N., D. Cattaneo, et al. (2004). "Delayed graft function in kidney transplantation." Lancet 364(9447): 1814-1827.

Pinsky, D. J., S. F. Yan, et al. (1995). "Hypoxia and modification of the endothelium: implications for regulation of vascular homeostatic properties." Semin Cell Biol 6(5): 283-294.

Portilla, D., G. Dai, et al. (2000). "Etomoxir-induced PPARalpha-modulated enzymes protect during acute renal failure." Am J Physiol Renal Physiol 278(4): F667-675.

Rajakumar, S. V., B. Lu, et al. (2010). "Deficiency or inhibition of CD73 protects in mild kidney ischemia-reperfusion injury." Transplantation 90(12): 1260-1264.

Renner, B., D. Strassheim, et al. (2010). "B cell subsets contribute to renal injury and renal protection after ischemia/reperfusion." J Immunol 185(7): 4393-4400.

Salmela, K., L. Wramner, et al. (1999). "A randomized multicenter trial of the anti-ICAM-1 monoclonal antibody (enlimomab) for the prevention of acute rejection and delayed onset of graft function in cadaveric renal transplantation: a report of the European Anti-ICAM-1 Renal Transplant Study Group." Transplantation 67(5): 729736.

Savransky, V., R. R. Molls, et al. (2006). "Role of the T-cell receptor in kidney ischemiareperfusion injury." Kidney Int 69(2): 233-238.

Schneider, M. P., J. C. Sullivan, et al. (2010). "Protective role of extracellular superoxide dismutase in renal ischemia/reperfusion injury." Kidney Int 78(4): 374-381. 
Sharfuddin, A. A., R. M. Sandoval, et al. (2009). "Soluble thrombomodulin protects ischemic kidneys." J Am Soc Nephrol 20(3): 524-534.

Sharples, E. J., N. Patel, et al. (2004). "Erythropoietin protects the kidney against the injury and dysfunction caused by ischemia-reperfusion." J Am Soc Nephrol 15(8): 21152124.

Shi, Y., V. Y. Melnikov, et al. (2000). "Downregulation of the calpain inhibitor protein calpastatin by caspases during renal ischemia-reperfusion." Am J Physiol Renal Physiol 279(3): F509-517.

Shigeoka, A. A., T. D. Holscher, et al. (2007). "TLR2 is constitutively expressed within the kidney and participates in ischemic renal injury through both MyD88-dependent and -independent pathways." J Immunol 178(10): 6252-6258.

Shoskes, D. A. and J. M. Cecka (1998). "Deleterious effects of delayed graft function in cadaveric renal transplant recipients independent of acute rejection." Transplantation 66(12): 1697-1701.

Sikorski, E. M., T. Hock, et al. (2004). "The story so far: Molecular regulation of the heme oxygenase-1 gene in renal injury." Am J Physiol Renal Physiol 286(3): F425-441.

Singbartl, K. and K. Ley (2000). "Protection from ischemia-reperfusion induced severe acute renal failure by blocking E-selectin." Crit Care Med 28(7): 2507-2514.

Sivarajah, A., P. K. Chatterjee, et al. (2002). "Agonists of peroxisome-proliferator activated receptor-alpha (clofibrate and WY14643) reduce renal ischemia/reperfusion injury in the rat." Med Sci Monit 8(12): BR532-539.

Sivarajah, A., P. K. Chatterjee, et al. (2003). "Agonists of peroxisome-proliferator activated receptor-gamma reduce renal ischemia/reperfusion injury." Am J Nephrol 23(4): 267-276.

Sutton, T. A., K. J. Kelly, et al. (2005). "Minocycline reduces renal microvascular leakage in a rat model of ischemic renal injury." Am J Physiol Renal Physiol 288(1): F91-97.

Sutton, T. A., H. E. Mang, et al. (2003). "Injury of the renal microvascular endothelium alters barrier function after ischemia." Am J Physiol Renal Physiol 285(2): F191-198.

Takada, M., K. C. Nadeau, et al. (1997). "The cytokine-adhesion molecule cascade in ischemia/reperfusion injury of the rat kidney. Inhibition by a soluble P-selectin ligand." J Clin Invest 99(11): 2682-2690.

Teoh, N., I. Leclercq, et al. (2003). "Low-dose TNF-alpha protects against hepatic ischemiareperfusion injury in mice: implications for preconditioning." Hepatology 37(1): 118128.

Thompson, L. F., H. K. Eltzschig, et al. (2004). "Crucial role for ecto-5'-nucleotidase (CD73) in vascular leakage during hypoxia." J Exp Med 200(11): 1395-1405.

Thornton, M. A., R. Winn, et al. (1989). "An evaluation of the neutrophil as a mediator of in vivo renal ischemic-reperfusion injury." Am J Pathol 135(3): 509-515.

Thurman, J. M., A. M. Lenderink, et al. (2007). "C3a is required for the production of CXC chemokines by tubular epithelial cells after renal ishemia/reperfusion." J Immunol 178(3): 1819-1828.

Thurman, J. M., D. Ljubanovic, et al. (2003). "Lack of a functional alternative complement pathway ameliorates ischemic acute renal failure in mice." J Immunol 170(3): 15171523. 
Togel, F., Z. Hu, et al. (2005). "Administered mesenchymal stem cells protect against ischemic acute renal failure through differentiation-independent mechanisms." Am J Physiol Renal Physiol 289(1): F31-42.

Toyokuni, S. (1999). "Reactive oxygen species-induced molecular damage and its application in pathology." Pathol Int 49(2): 91-102.

Van Waarde, A., M. E. Stromski, et al. (1989). "Protection of the kidney against ischemic injury by inhibition of 5'-nucleotidase." Am J Physiol 256(2 Pt 2): F298-305.

Vincenti, F., A. Dritselis, et al. (2011). "Belatacept." Nat Rev Drug Discov 10(9): 655-656.

Wang, Y., H. Xu, et al. (2001). "Intestinal ischemia induces late preconditioning against myocardial infarction: a role for inducible nitric oxide synthase." Cardiovasc Res 49(2): 391-398.

Weinbrenner, C., M. Nelles, et al. (2002). "Remote preconditioning by infrarenal occlusion of the aorta protects the heart from infarction: a newly identified non-neuronal but PKC-dependent pathway." Cardiovasc Res 55(3): 590-601.

Weitz, M., O. Amon, et al. (2011). "Prophylactic eculizumab prior to kidney transplantation for atypical hemolytic uremic syndrome." Pediatr Nephrol 26(8): 1325-1329.

Wolfs, T. G., W. A. Buurman, et al. (2002). "In vivo expression of Toll-like receptor 2 and 4 by renal epithelial cells: IFN-gamma and TNF-alpha mediated up-regulation during inflammation." J Immunol 168(3): 1286-1293.

Wu, H., G. Chen, et al. (2007). "TLR4 activation mediates kidney ischemia/reperfusion injury." J Clin Invest 117(10): 2847-2859.

Yamada, K., T. Miwa, et al. (2004). "Critical protection from renal ischemia reperfusion injury by CD55 and CD59." J Immunol 172(6): 3869-3875.

Yamauchi, J., R. Schramm, et al. (2003). "Improvement of microvascular graft equilibration and preservation in non-heart-beating donors by warm preflush with streptokinase." Transplantation 75(4): 449-453.

Yang, C., V. Kaushal, et al. (2008). "Transcriptional activation of caspase- 6 and -7 genes by cisplatin-induced p53 and its functional significance in cisplatin nephrotoxicity." Cell Death Differ 15(3): 530-544.

Yokota, N., M. Burne-Taney, et al. (2003). "Contrasting roles for STAT4 and STAT6 signal transduction pathways in murine renal ischemia-reperfusion injury." Am J Physiol Renal Physiol 285(2): F319-325.

Yokota, N., M. O'Donnell, et al. (2003). "Protective effect of HMG-CoA reductase inhibitor on experimental renal ischemia-reperfusion injury." Am J Nephrol 23(1): 13-17.

Yoshida, J., K. S. Ozaki, et al. (2010). "Ex vivo application of carbon monoxide in UW solution prevents transplant-induced renal ischemia/reperfusion injury in pigs." Am J Transplant 10(4): 763-772.

Younes, M., M. H. Schoenberg, et al. (1984). "Oxidative tissue damage following regional intestinal ischemia and reperfusion in the cat." Res Exp Med (Berl) 184(4): 259-264.

Ysebaert, D. K., K. E. De Greef, et al. (2004). "T cells as mediators in renal ischemia/reperfusion injury." Kidney Int 66(2): 491-496.

Zarek, P. E., C. T. Huang, et al. (2008). "A2A receptor signaling promotes peripheral tolerance by inducing $\mathrm{T}$-cell anergy and the generation of adaptive regulatory $\mathrm{T}$ cells." Blood 111(1): 251-259.

Zhang, Z. X., S. Wang, et al. (2008). "NK cells induce apoptosis in tubular epithelial cells and contribute to renal ischemia-reperfusion injury." J Immunol 181(11): 7489-7498. 
Zhou, W., C. A. Farrar, et al. (2000). "Predominant role for C5b-9 in renal ischemia/reperfusion injury." J Clin Invest 105(10): 1363-1371.

Zimmerman, R. F., P. U. Ezeanuna, et al. (2011). "Ischemic preconditioning at a remote site prevents acute kidney injury in patients following cardiac surgery." Kidney Int.

Zimmermann, H. (1992). "5'-Nucleotidase: molecular structure and functional aspects." Biochem J 285 ( Pt 2): 345-365. 


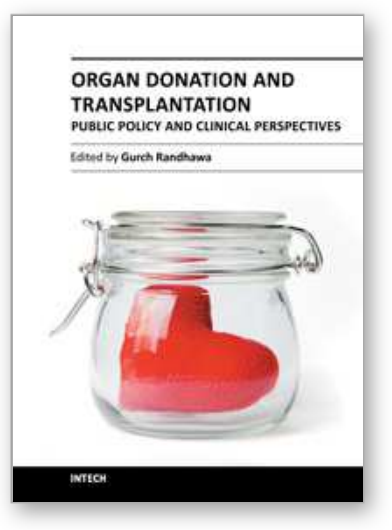

\author{
Organ Donation and Transplantation - Public Policy and Clinical \\ Perspectives \\ Edited by Dr. Gurch Randhawa
}

ISBN 978-953-51-0039-3

Hard cover, 284 pages

Publisher InTech

Published online 08, February, 2012

Published in print edition February, 2012

Transplantation has succeeded in prolonging the lives of those fortunate enough to have received the gift of a body organ. Alongside this life-saving development, there lies another sadder side to the story - there are not enough organs to meet the ever increasing demand. This not only places an increasing emotional and physical burden among the waiting patients and families but heaps a great financial burden upon health services. This book provides an analysis and overview of public policy developments and clinical developments that will hopefully ensure an increased availability of organs and greater graft survival. Medical, policy, and academic experts from around the world have contributed chapters to the book.

\title{
How to reference
}

In order to correctly reference this scholarly work, feel free to copy and paste the following:

Siddharth Rajakumar and Karen Dwyer (2012). Ischaemia Reperfusion Injury in Kidney Transplantation, Organ Donation and Transplantation - Public Policy and Clinical Perspectives, Dr. Gurch Randhawa (Ed.), ISBN: 978953-51-0039-3, InTech, Available from: http://www.intechopen.com/books/organ-donation-and-transplantationpublic-policy-and-clinical-perspectives/ischaemia-reperfusion-injury-in-kidney-transplantation

\section{INTECH}

open science | open minds

\section{InTech Europe}

University Campus STeP Ri Slavka Krautzeka 83/A 51000 Rijeka, Croatia Phone: +385 (51) 770447

Fax: +385 (51) 686166 www.intechopen.com

\section{InTech China}

Unit 405, Office Block, Hotel Equatorial Shanghai No.65, Yan An Road (West), Shanghai, 200040, China 中国上海市延安西路65号上海国际贵都大饭店办公楼405单元 Phone: +86-21-62489820

Fax: $+86-21-62489821$ 
(C) 2012 The Author(s). Licensee IntechOpen. This is an open access article distributed under the terms of the Creative Commons Attribution 3.0 License, which permits unrestricted use, distribution, and reproduction in any medium, provided the original work is properly cited. 